\title{
Bilateral facial nerve palsy as the sole initial symptom of syphilis: a case report
}

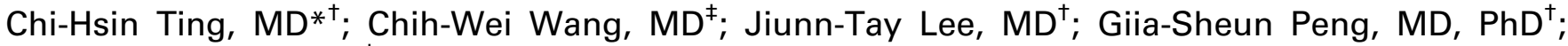 \\ Fu-Chi Yang, MD, $\mathrm{PhD}^{\dagger}$
}

\section{ABSTRACT}

Bilateral facial nerve palsy is an exceedingly rare condition and presents a diagnostic challenge. Bilateral facial nerve palsy may result from cranial trauma, congenital abnormalities, inflammation, infiltration, or infection, but is rarely associated with syphilis. Here, we report a case of syphilis in which bilateral facial nerve palsy was the only initial symptom.

A 22-year-old man presented at our emergency department with isolated bilateral facial nerve palsy. Results for initial serum and cerebrospinal fluid examinations were normal, including the rapid plasma reagin titer. One week later, the patient developed rashes on the torso, palms, and soles. At this time, a high serum rapid plasma reagin titer was detected, and the Treponema pallidum particle agglutination test was positive. Once the tests were confirmed, the patient admitted to a history of unprotected sexual behavior. Penicillin G treatment was effective, and a 3-month followup examination demonstrated a complete recovery.We recommend that syphilis be considered when diagnosing sexually experienced young men presenting with bilateral facial nerve palsy, even in the absence of skin manifestations. Failure to recognize facial signs of syphilis could result in inappropriate management, affecting the patient's clinical outcome.

\section{RÉSUMÉ}

La paralysie bilatérale du nerf facial est un trouble extrêmement rare, qui pose des difficultés de diagnostic. La paralysie bilatérale du nerf facial peut résulter d'un traumatisme crânien, d'anomalies congénitales, d'une inflammation, d'une infiltration ou d'une infection, mais elle est rarement associée à la syphilis. Sera exposé ici un cas de syphilis dans lequel la paralysie bilatérale du nerf facial était le seul symptôme initial de la maladie.Un homme de 22 ans est venu consulter au service des urgences pour une paralysie bilatérale et isolée du nerf facial. Les analyses sérologiques et l'examen du liquide céphalorachidien se sont révélés normaux au départ, y compris le test rapide de la réagine plasmatique. Toutefois, une semaine plus tard, des éruptions cutanées sont apparues sur le tronc, la paume des mains et la plante des pieds. Un titre élevé de réagine plasmatique a alors été détecté au test sérologique rapide, et l'épreuve d'agglutination passive de Treponema pallidum s'est avérée positive. Une fois les résultats confirmés, le patient a admis avoir eu un comportement sexuel risqué dans le passé. Le traitement par la pénicilline $\mathrm{G}$ a agi efficacement, et l'examen de suivi au bout de 3 mois a permis d'établir l'obtention de la guérison complète.

Les auteurs recommandent donc que soit envisagé le diagnostic de syphilis chez les jeunes hommes ayant une vie sexuelle active et présentant une paralysie bilatérale du nerf facial, même en l'absence de manifestations cutanées. Le fait de ne pas reconnaître les signes faciaux de la syphilis pourrait conduire à une prise en charge inadaptée, et se répercuter sur les résultats cliniques.

Keywords: bilateral facial nerve palsy, maculopapular rash, rapid plasma reagin, syphilis, Treponema pallidum particle agglutination

\section{INTRODUCTION}

Bilateral facial nerve palsy is a rare condition, accounting for less than $2 \%$ of all cases of facial palsy. Its incidence is reported to approximately 1 in $5,000,000 .{ }^{1}$ Unlike unilateral facial nerve palsy, bilateral facial nerve palsy seldom presents secondary to Bell's palsy. Instead, it often indicates a serious underlying medical condition. Known etiologies include congenital abnormalities, cranial trauma, infection, inflammation, metabolic and autoimmune disorders, stroke, neoplasia, and iatrogenesis. ${ }^{2,3}$

In this study, we report the case of a 22-year-old man presenting with bilateral facial nerve palsy, who was later diagnosed with syphilis.

From the *Department of Internal Medicine, Taichung Armed Forces General Hospital, Taichung, Taiwan; tDepartment of Neurology; and ‡Department of Radiology, Tri-Service General Hospital, National Defense Medical Center, Taipei, Taiwan.

Correspondence to: Dr. Fu-Chi Yang, Department of Neurology, Tri-Service General Hospital, National Defense Medical Center No. 325, Section 2, Cheng-Kung Road, Neihu 114, Taipei, Taiwan, R.O.C.; Email: fuji-yang@yahoo.com.tw 


\section{CASE REPORT}

A 22-year-old man with no medical history was admitted to the emergency department (ED) of our hospital due to bilateral facial nerve palsy (Figure 1A). For approximately 2 days prior to admission, he was unable to close his eyelids (Figure 1B). At the time of admission, he denied having any sexually transmitted disease and reported no history of unprotected sexual behavior or sexual activity with other men. We collected his history, and the patient denied having a chancre in the previous weeks as well as any history of tick exposure. The values for vital signs at the initial visit were systolic/diastolic blood pressure of $101 / 56 \mathrm{~mm} \mathrm{Hg}$, body temperature of $36.0^{\circ} \mathrm{C}\left(96.8^{\circ} \mathrm{F}\right)$, pulse rate of 61 beats/minute, and respiratory rate of 16 breaths/minute. Physical examination confirmed bilateral facial nerve palsy of the peripheral type (involving an entire side of the face), while examination of other cranial nerves revealed no abnormalities. Facial nerve palsy is diagnosed on the basis of a physical examination of facial expression, and the face should appear symmetric. First, the number of wrinkles apparent on either side of the forehead should be the same. Second, the nasolabial folds should be equal. Third, the corners of the mouth should be at the same height. The central type of facial palsy leads to paralysis of the lower half of one side of the face, whereas the peripheral type is characterized by total facial paralysis, that is, paralysis of both the upper and lower halves of the face on the same side. ${ }^{4}$ Muscle power was normal in all four extremities, sensory examination was unremarkable, and deep tendon reflexes were present. There were no cerebellar signs. No skin or genital abnormality was found during this visit. Laboratory tests revealed a hemoglobin level of $132 \mathrm{~g} / \mathrm{L}$ (normal range, $116-168 \mathrm{~g} / \mathrm{L})$, a white cell count of $11.53 \times 109 / \mathrm{L}$
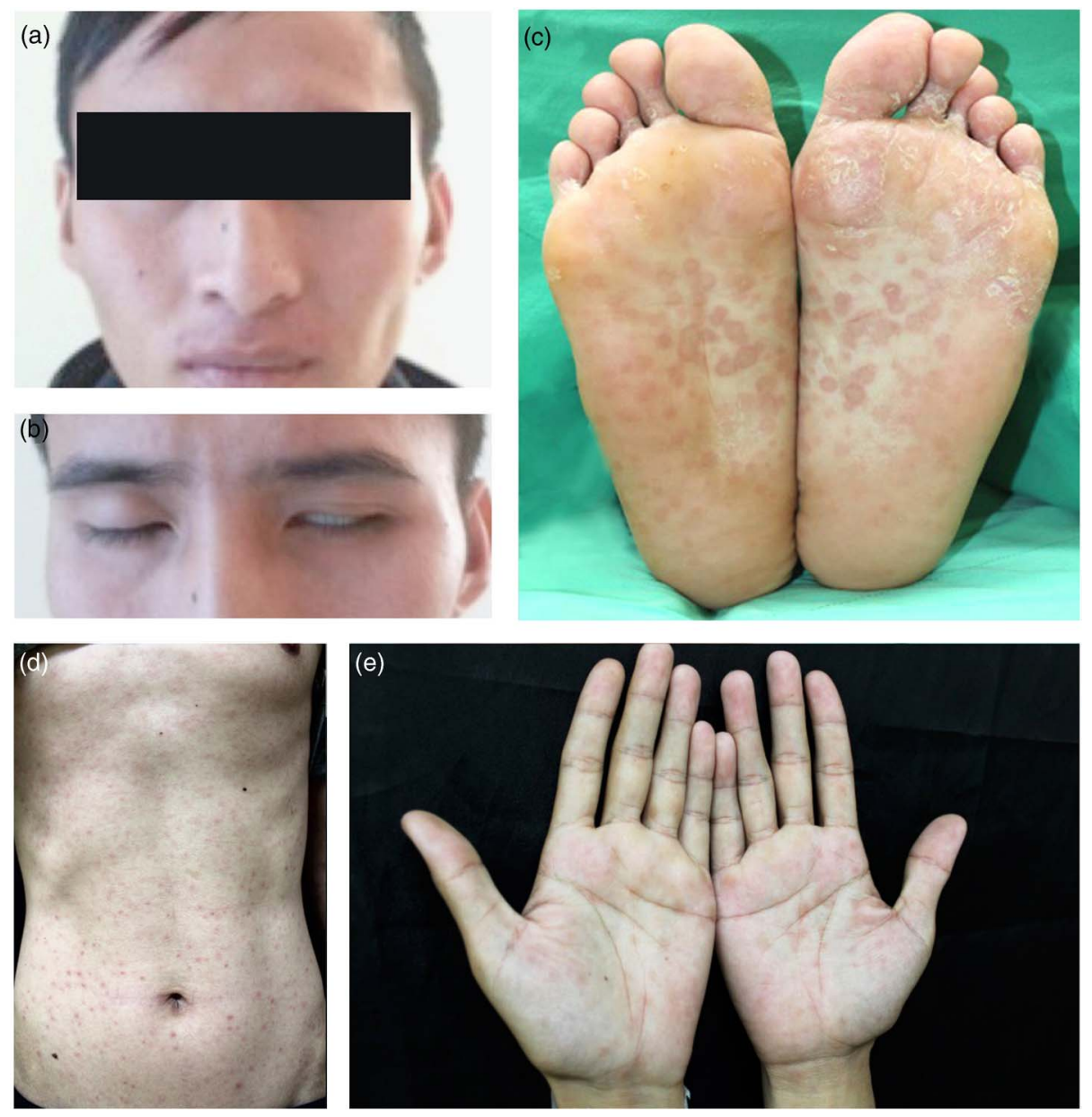

Figure 1. A. A 22-year-old man with bilateral facial paralysis. B. Bilateral facial nerve palsy (peripheral type) was observed, but it was more pronounced on the left side. C-E. Red maculopapular rashes manifested on the trunk, palms of the hands, and soles of the feet. 
(normal range, 4.5-11 $\times 109 / \mathrm{L})$ (78.7\% neutrophils), and a C-reactive protein concentration of $15.6 \mathrm{mg} / \mathrm{L}$ (normal range, $0.0-5.0 \mathrm{mg} / \mathrm{L}$ ). Examination of the cerebrospinal fluid (CSF), obtained by lumbar puncture, revealed no nucleated cells and one red cell. The patient's glucose level was $3.61 \mathrm{mmol} / \mathrm{L}$ (normal range, $2.5-4.2 \mathrm{mmol} / \mathrm{L}$ ), and protein level was $0.25 \mathrm{~g} / \mathrm{L}$ (normal range, $0.15-0.45 \mathrm{~g} / \mathrm{L}$ ). Serum India ink staining and serum antibody tests for Lyme disease, Cryptococcus, and human immunodeficiency virus (HIV) yielded negative results. Serum levels of antineutrophil cytoplasmic antibodies and thyroid-stimulating hormone were unremarkable. The screening tests for syphilis include the rapid plasma reagin and Venereal Disease Research Laboratory (VDRL) tests. At the initial presentation, we performed the serologic rapid plasma reagin test, which was non-reactive. Other serologic biochemical and metabolic profiles were normal. The CSF VDRL test and the polymerase chain reaction test for herpes were non-reactive. Because the serologic rapid plasma reagin and CSF VDRL screening tests were non-reactive at the first presentation, we did not perform the serologic Treponema pallidum particle agglutination test at that time. The diagnosis at discharge after this initial visit was bilateral facial nerve palsy of an undetermined cause. We prescribed oral prednisolone for bilateral facial nerve palsy and a neurology outpatient department follow-up.

One week later, a red maculopapular rash appeared on the trunk and on all four extremities of the patient (Figure 1C-E), and he returned to our ED. At that time, the ED doctor consulted a neurologist, who noted that the bilateral facial nerve palsy was partially improved by steroid treatment during the second visit. At this time, the Treponema pallidum particle agglutination test showed a high serum titer (1:1280). A repeat lumbar puncture showed three nucleated cells and three red cells. Glucose and protein levels were normal, and the CSF VDRL test remained non-reactive. However, the rapid plasma reagin serology results were remarkable (1:32). Subsequently, the patient was diagnosed with syphilis. Table 1 summarizes the laboratory data at the first and second presentations, including data for both blood and CSF tests. At the second visit, we attempted to identify the source of the infection. The patient reported two events of unprotected genital sexual exposure with a sex worker approximately 3 and 6 months prior to symptom onset. He denied any unprotected sexual activity prior to these two events.
Although magnetic resonance imaging (MRI) is not routinely performed in the ED, we had the opportunity to perform brain MRI and nerve conduction velocity testing for this patient after hospitalization, to rule out other organic etiologies such as tumor, other infections, or inflammation. Nerve conduction velocity testing was conducted on all four limbs and revealed no major abnormal findings. Facial stimulation testing showed reduced amplitude of compound motor action potentials, which was more severe on the right side. The blink reflex did not show bilateral latencies of R1, ipsilateral R2, or contralateral R2, indicating bilateral facial neuropathy, which was more severe on the left side. Brain MRI (3.0 T, 3D T1-weighted fast spoiled gradient echo imaging, 1.4-mm slice thickness) was performed in the supine position using gadolinium contrast medium $(0.1 \mathrm{mmol} / \mathrm{kg}$, given intravenously) to evaluate the cranial nerves. Contrast enhancement was

\begin{tabular}{|c|c|c|c|c|}
\hline & \multicolumn{2}{|c|}{ First presentation } & \multicolumn{2}{|c|}{ Second presentation } \\
\hline & \multicolumn{2}{|l|}{$\begin{array}{c}(2012 / 12 / \\
04)\end{array}$} & \multicolumn{2}{|l|}{$\begin{array}{c}(2012 / 12 / \\
11)\end{array}$} \\
\hline & Blood & CSF & Blood & CSF \\
\hline WBC $\left(\times 10^{9} / \mathrm{L}\right)$ & 11.5 & 0 & 6.2 & 3 \\
\hline $\operatorname{RBC}\left(\times 10^{12} / \mathrm{L}\right)$ & 4.4 & 1 & 4.5 & 3 \\
\hline $\mathrm{Hb}(\mathrm{g} / \mathrm{L})$ & 132 & - & 135 & - \\
\hline CRP (mg/L) & 15.6 & - & 26 & - \\
\hline T. protein $(\mathrm{g} / \mathrm{L})$ & 68 & 0.25 & 69 & 0.25 \\
\hline Glucose (mmol/L) & 5.99 & 3.61 & 5.27 & 3.5 \\
\hline RPR titer & $\begin{array}{c}\text { non- } \\
\text { reactive }\end{array}$ & - & $1: 32$ & - \\
\hline VDRL titer & - & $\begin{array}{l}\text { non- } \\
\text { reactive }\end{array}$ & - & $\begin{array}{c}\text { non- } \\
\text { reactive }\end{array}$ \\
\hline TPPA titer & - & - & $>1: 1280$ & $\begin{array}{c}\text { non- } \\
\text { reactive }\end{array}$ \\
\hline Anti-HIV Ab & neg. & neg. & neg. & neg. \\
\hline HSV IGM Ab & neg. & neg. & neg. & neg. \\
\hline VZV IGM Ab & neg. & neg. & neg. & neg. \\
\hline CMV IGM Ab & neg. & neg. & neg. & neg. \\
\hline EBV VCA IGM Ab & neg. & neg. & neg. & neg. \\
\hline TB Complex- PCR & neg. & neg. & neg. & neg. \\
\hline \multicolumn{5}{|c|}{ 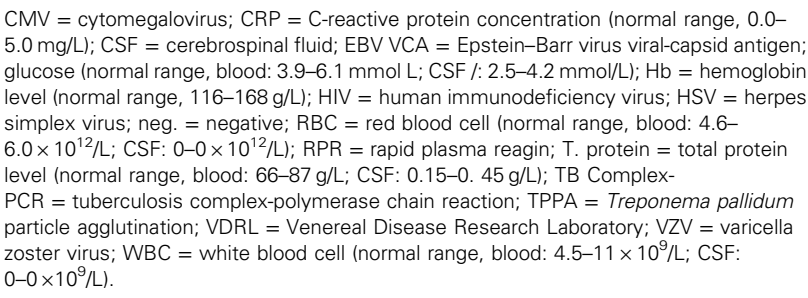 } \\
\hline
\end{tabular}




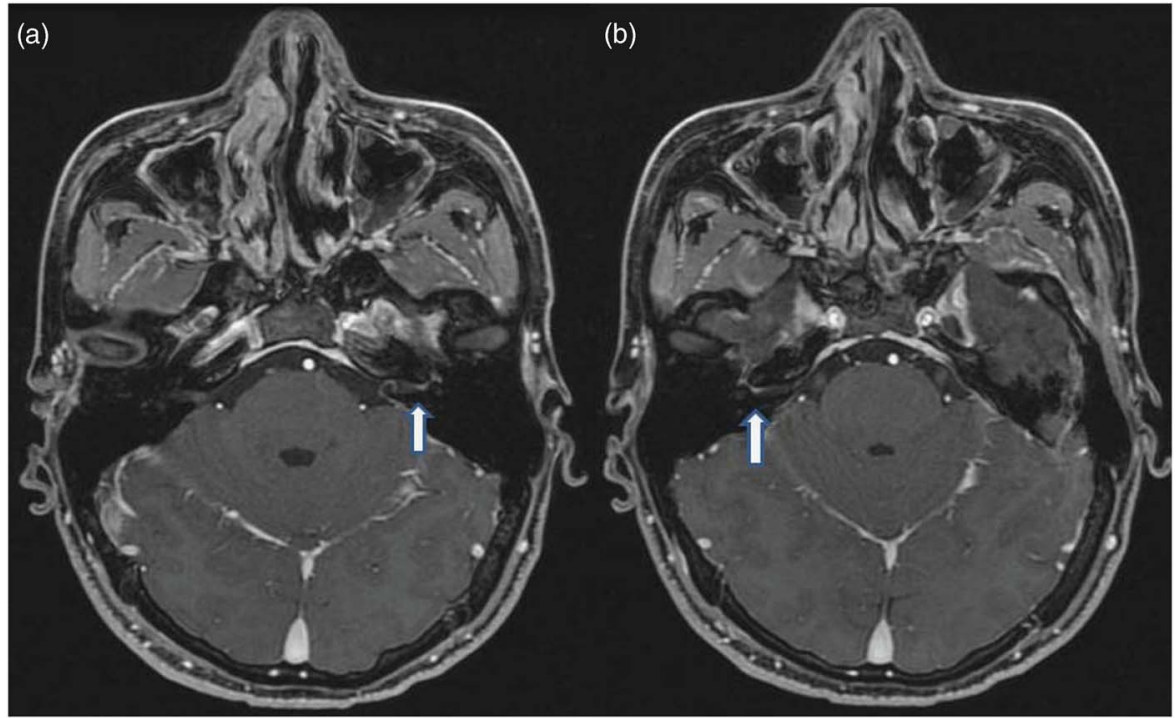

Figure 2. Gadolinium-enhanced $M R I$ showing regular enhancement of the internal auditory canal, labyrinthine, and anterior tympanic portions of the left $(A$, see arrow) and right facial nerve ( $B$, see arrow).

noted in the facial nerves in the region of the internal auditory canals and temporal bones (Figure 2), suggesting bilateral inflammation or infection. The brain showed normal ventricular size, as well as normal grey/ white matter and meningeal signal intensities.

Intramuscular treatment with benzathine penicillin (2.4 million units) in a single dose was initiated. Within 1 week, facial nerve function and the red maculopapular rashes over the trunk and all four extremities began to improve. Complete recovery was noted at the 3 -month follow-up examination.

\section{DISCUSSION}

Bilateral facial nerve palsy is an exceedingly rare condition, accounting for less than $2 \%$ of all cases of facial palsy. Unlike unilateral facial nerve palsy, which is usually idiopathic, bilateral facial nerve palsy often indicates a serious underlying medical condition, which can include Lyme disease, sarcoidosis, Guillain-Barré syndrome, diabetic (mellitus) neuropathy, and multiple idiopathic cranial neuropathies. ${ }^{1}$ Here, we report the case of a patient with syphilis who presented with bilateral facial nerve palsy as his initial symptom.

Syphilis is a sexually transmitted disease caused by the spirochete bacterium $T$. pallidum. With the advent of penicillin treatment and an aggressive public health approach, the annual incidence rate of syphilis in the United States decreased by about 95\% between 1943 and 2000..$^{5}$ Between 2000 and 2008, however, the number of cases of syphilis infection in the United States has more than doubled. ${ }^{5}$ These cases especially involve men who engage in homosexual behavior and are co-infected with HIV. ${ }^{5}$ Overall, nearly 12 million new syphilis infections occur each year, with the most affected regions including South America, Southeast Asia, China, and sub-Saharan Africa. ${ }^{5}$ The signs and symptoms of syphilis vary depending on the stage in which they present. The primary stage involves the appearance of a chancre- - a round, painless ulcer or sore on the area of the skin initially exposed to the infection. Left untreated for 2 to 4 weeks, the disease progresses to the secondary stage with the clinical manifestation of a rash on the palms of the hands and soles of the feet. ${ }^{6}$ Nervous system involvement (neurosyphilis) can occur at any stage of the disease, striking at weeks to years after the initial infection. It is, however, most commonly observed in the final, tertiary stage. ${ }^{6}$ Although neurosyphilis is often asymptomatic, ${ }^{6}$ it can sometimes manifest as visual disturbances, hearing loss, and facial palsy. ${ }^{7}$

In the case described here, the patient presented with isolated bilateral facial nerve palsy as the initial manifestation of early-stage syphilis. Laboratory examinations, including CSF and serologic tests, yielded normal findings at the initial presentation. It was subsequent to the appearance of a rash on the trunk and all four extremities 1 week after admission that serum rapid plasma reagin 


\begin{tabular}{|c|c|c|c|c|c|}
\hline \multirow[b]{2}{*}{ Test } & \multicolumn{4}{|c|}{ Sensitivity during stage of infection, $\%$ (range) } & \multirow{2}{*}{$\begin{array}{l}\text { Specificity } \\
\% \text { (range) }\end{array}$} \\
\hline & Primary & Secondary & Latent & Late & \\
\hline \multicolumn{6}{|c|}{ Non-treponemal tests } \\
\hline VDRL & $78(74-87)$ & 100 & $96(88-100)$ & $71(37-94)$ & 98 (96-99) \\
\hline RPR & $86(77-99)$ & 100 & $98(95-100)$ & 73 & 98 (93-99) \\
\hline \multicolumn{6}{|c|}{ Treponemal tests } \\
\hline TPPA & $88(86-100)$ & 100 & 100 & NA & $96(95-100)$ \\
\hline TPHA & 86 & 100 & 100 & 99 & 96 \\
\hline
\end{tabular}

and Treponema pallidum particle agglutination titers were remarkable (1:32 and 1:1280, respectively). Notably, CSF VDRL remained non-reactive. The patient denied any history of unprotected sexual behavior until the diagnosis was made. Other cases of facial nerve palsy associated with syphilis have been reported in the literature. In 1929, Strauss reviewed 37 cases of syphilis with bilateral facial nerve palsy, of which 23 were in the early stage of syphilis, 6 were in the late stage, and 8 were in an undetermined stage. ${ }^{8}$ A review article by Keane found that 2 of 43 cases of bilateral facial nerve palsy were induced by syphilis infection. $^{7}$ A potential differential diagnosis of bilateral facial nerve palsy could be syphilitic meningitis, which was reported by Merritt et al. to be the most common etiology involving cranial nerves, especially the facial and auditory nerves. ${ }^{9}$ In an analysis of 34 patients, unilateral facial nerve involvement was noted in 16 cases, whereas bilateral palsy was observed in 2 cases. ${ }^{9}$ However, based on the clinical symptoms and CSF findings, syphilitic meningitis was less likely in the current case.

On the basis of the skin rashes over the trunk and extremities as well as the laboratory data showing that CSF VDRL was non-reactive, we deduced that the syphilis infection was in the secondary stage before penicillin $G$ treatment was initiated. Had the skin rashes not appeared, physicians could have easily misdiagnosed the cause underlying the bilateral facial nerve palsy. Because a detailed history and serum syphilis tests were necessary to provide early diagnostic clues, we recommend that syphilis infection be considered in the differential diagnosis of bilateral facial nerve palsy. The diagnosis of syphilis is based on both non-treponemal and treponemal serologic tests. Non-treponemal tests are often screening tests and include the rapid plasma reagin and VDRL tests. Treponemal tests are used for confirmation after a reactive non-treponemal test and include the Treponema pallidum particle agglutination and Treponema pallidum hemagglutination assays (TPHA). The sensitivity and specificity of serologic tests for syphilis are listed in Table 2. The positive predictive value or negative predictive value of syphilis tests depends on disease prevalence in the population tested. ${ }^{10}$ The positive predictive value of syphilis tests can reach $90 \%$ as syphilis prevalence or clinical suspicion increases in the population tested. ${ }^{10}$ As noted in Table 2, the sensitivity of the serologic rapid plasma reagin test at the primary syphilis stage is only $74 \%-87 \%$ (well below $100 \%)$. For our case, the serologic rapid plasma reagin test was non-reactive at the first presentation, causing us to miss the diagnosis of syphilis at this time.

\section{TAKE-HOME CLINICAL MESSAGE PERTINENT TO EMERGENCY PHYSICIANS}

Despite the negative initial screening test, it was considered important to record the patient's sexual history and follow up on his condition. Because of the only moderate sensitivity of the rapid plasma reagin test, we believe syphilis should be included in the differential diagnosis for bilateral facial nerve palsy, and patients should be closely followed even when the initial screening test is negative. We believe this to be especially true for bilateral facial nerve palsy in young people, or in populations with high risk of sexual exposure. Emergency physicians should be aware of syphilis as a rare but possible etiology of bilateral facial nerve palsy. Syphilis might be making a comeback in young men with a sexual history, especially in men with homosexual exposure and HIV. Failure to recognize the facial signs of syphilis could result in inappropriate 
management, which could, in turn, affect the clinical outcome. For young adults presenting to the ED with bilateral facial nerve palsy, a thorough history of sexual exposure and serum rapid plasma reagin and Treponema pallidum particle agglutination is warranted. More thorough assessments, including additional laboratory and radiological tests, may also be necessary. Furthermore, if a patient with an initial presentation of bilateral facial nerve palsy and a negative syphilis screen reports a history of exposure to sex workers in places with a higher incidence of syphilis, the use of empiric penicillin may be warranted.

Competing interests: None declared.

\section{REFERENCES}

1. Pothiawala S, Lateef F. Bilateral facial nerve palsy: a diagnostic dilemma. Case Rep Emerg Med 2012;ID458371, 1-3.
2. Sim JE, Choi YC, Kim WJ. Facial diplegia in Plasmodium vivax malaria. 7 Clin Neurol 2010;6(2):102-3.

3. Kilic R, Ozdek A, Felek S, et al. A case presentation of bilateral simultaneous Bell's palsy. Am 7 Otolaryngol 2003;24 (4):271-3.

4. Campbell WW. Defong's the neurologic examination. Philadelphia: Lippincott Williams and Wilkins; 2005:217-24.

5. Longo DL, Fauci AS, Kasper DL, et al. Harrison's principles of internal medicine. Boston: McGraw-Hill;2011:1038-46.

6. Smith MM, Anderson JC. Neurosyphilis as a cause of facial and vestibulocochlear nerve dysfunction: MR imaging features. Am 7 Neuroradiol 2000;21(9):1673-5.

7. Keane JR. Bilateral seventh nerve palsy: analysis of 43 cases and review of the literature. Neurology 1994;44(7): 1198-202.

8. Strauss MJ. Diplegia facialis in early syphilis: a report of a case. Arch Dermatol Syph 1929;20(3):306-14.

9. Merritt HH, Adams RD, Soloman HC. Neurosyphilis. New York: Oxford University Press;1946:38-41.

10. Seña AC, White BL, Sparling PF. Novel Treponema pallidum serologic tests: a paradigm shift in syphilis screening for the 21st century. Clin Infect Dis 2010;51(6): 700-8. 